\title{
The comparison of core and geophysical log measurements obtained in the Nirex investigation of the Sellafield region
}

A. Kingdon, S. F. Rogers, C. J. Evans and N. R. Brereton

British Geological Survey, Keyworth, Nottingham, NG12 5GG, UK

\section{Abstract}

The Sellafield region, west Cumbria, is the focus of one of the most thorough geological investigations in the United Kingdom. The Sellafield Site is defined as an area immediately around the potential repository, extending $6.5 \mathrm{~km}$ north-south by $8 \mathrm{~km}$ eastwest. Twenty six deep boreholes were drilled within the area up to the end of 1995, with a total depth of approximately $28 \mathrm{~km}$. Most of these boreholes have been continuously cored, a total of over 17 kilometres of core, with average core recovery well in excess of $90 \%$. All boreholes were logged with a comprehensive suite of geophysical logs, including many state of the art tools. Laboratory physical property analysis of hundreds of sample cores has been carried out.

Pilot studies were carried out to compare and contrast datasets and to investigate the relationships between the different data scales. Various techniques, including fractal analysis and Artificial Neural Networks, were tried in order to explore the relationships of these data at a variety of measurement scales.

The pilot study was conducted in two stages:

(1) evaluation of the primary controlling factors of the physical properties;

(2) testing the validity of 'Up-scaling'.

The rocks of the Borrowdale Volcanic Group provided the most challenging problems due to the physical properties being dominated by fracturing and associated alteration zones.

Relationships between data types at different scales were established suggesting that the extrapolation of properties derived from core and wireline logs across three-dimensional seismic grids would allow an understanding of the properties throughout a three-dimensional volume 